\title{
HUBUNGAN PERILAKU SEKSUAL REMAJA DENGAN LINGKUNGAN DI SMK $X$ PEKANBARU
}

\author{
Nike Puspita Alwi ${ }^{1)}$, Ainil Fitri ${ }^{2)}$, Mutia Ulfa ${ }^{3)}$ \\ ${ }^{1}$ Fakultas Farmasi dan Ilmu Kesehatan, Universitas Abdurrab \\ email : nike.puspita.a@univrab.ac.id \\ ${ }^{2}$ Fakultas Farmasi dan Ilmu Kesehatan, Universitas Abdurrab \\ email : ainil.fitri@univrab.ac.id
}

\begin{abstract}
abstark
Masa remaja sebagai masa peralihan perkembangan masa anak - anak menjadi dewasa, yang rentan akan perilaku-perilaku negatif. Salah satunya adalah perilaku seksual berisiko. Lingkungan dapat menjadi faktor yang mempengaruhi perilaku seorang remaja. Tujuan penelitian ini adalah untuk mengidentifikasi hubungan lingkungan dengan perilaku seksual remaja. Desain penelitian bersifat komparatif dengan pendekatan crosssectional. Penelitian dilakukan dari bulan Oktober 2019 hingga April 2020 dengan pengumpulan data pada bulan Maret 2020 menggunakan kuesioner pada 152 orang siswa - siswi di SMK X Pekanbaru. Pengolahan data menunjukkan dengan pengujian Chi-Square. Dari hasil penelitian diketahui bahwa terdapat hubungan yang signifikan antara lingkungan dengan perilaku seksual pada siswa di SMK X Pekanbaru ( $P$ value $=0,043$ ) dengan $\alpha=0$,05. Saran bagi sekolah agar memberikan edukasi tentang perilaku seksual positif dan negatif, faktor-faktor yang dapat mempengaruhinya, resikonya serta meningkatkan penanaman nilai moral pada siswa-siswi mereka.
\end{abstract}

Keywords : perilaku, seksual, remaja, lingkungan.

abstract

Adolescence is a transitional period in the development of children into adults, who are vulnerable to negative behaviors. One of them is risky sexual behavior. Environment can be a factor that influences the behavior of a teenager. The purpose of this study was to identify the relationship between the environment and adolescent sexual behavior. The research design is comparative with a crosssectional approach. The research was conducted from October 2019 to April 2020 with data collection in March 2020 using a questionnaire on 152 students at SMK $X$ Pekanbaru. Data processing shows the Chi-Square test. From the research results it is known that there is a significant relationship between the environment and sexual behavior in students at SMKX Pekanbaru (P value $=0.043$ ) with $\alpha=$ 0.05. Suggestions for schools to provide education about positive and negative sexual behavior, factors that can influence it, the risks and increase the cultivation of moral values in their students.

Keywords: behavior, sexuality, adolescence, environment.

\section{PENDAHULUAN}

Istilah remaja (adolescence) berasal dari bahasa latin adolescence yang berarti tumbuh atau tumbuh menjadi dewasa.
Dalam pertumbuhan menuju dewasa, membagi periode remaja ke dalam tiga tingkatan, yaitu 1) Periode remaja awal; 2) Periode remaja pertengahan; dan 3) 
Periode remaja lanjut (Muis, dkk. 2015).

Pada masa remaja terjadi perubahan fisik sangat cepat, yang tidak seimbang dengan perubahan kejiwaan (mental emosional). Perubahan fisik pada remaja ditandai dengan munculnya tanda-tanda seks, dan tandatanda seks primer yaitu berhubungan langsung dengan organ seks, dan tandatanda seks sekunder pria seperti perubahan suara, tumbuhnya jakun, penis dan buah zakar bertambah besar, terjadinya ereksi dan ejakulasi, dada lebih lebar, badan berotot, tumbuhnya kumis, jambang dan bulu-bulu disekitar kemaluan dan ketiak. Pada perempuan pinggul melebar, pertumbuhan rahim dan vagina, payudara membesar, tumbuhnya rambut di ketiak dan sekitar kemaluan (Irianto, 2015).

Berbagai perkembangan yang terjadi pada remaja sedikit banyaknya mempengaruhi terhadap perilaku yang mereka munculkan termasuk perilaku seksual mereka. Menurut Martopo (2016) macam perilaku seksual yaitu berpegangan tangan, berpelukan, berfantasi, cium kering (dilakukan pada pipi, tangan, dan rambut), cium bibir, Masturbasi/onani, seks oral (rangsangan seksual yang dilakukan mulut pada kelamin pasangan), meraba, petting basah (menggesekkan alat kelamin tanpa berpakaian), dan petting kering (menggesekkan alat kelamin masih menggunakan pakaian). Beberapa perilaku seksual yang dilakukan oleh remaja pada umumnya yaitu dengan berdandan, berfantasi seksual, mengobrol tentang seksual, bergaul dengan lawan jenis, menyalurkan lewat mimpi basah, menonton film porno, dan melakukan hubungan seksual non penetrasi (berciuman, berpelukan, dan bergandengan tangan).

Faktor-faktor yang mempengaruhi perilaku seksual remaja adalah paparan media pornografi, pengaruh teman sebaya, tingkat ketaatan agama remaja, tingkat pengetahuan remaja mengenai perilaku seksual yang rendah (Tristiadi, 2016). Selain itu faktor menyebabkan perilaku seksual pada remaja adalah perubahan-perubahan hormonal yang meningkatkan hasrat seksual remaja, kurangnya informasi dari orang tua, dan lingkungan (Cece, dkk. 2017).

Hasil survei Depertemen of Health \&
Human Services (2018) terhadap siswa sekolah menengah (SMA) di Amerika Serikat didapatkan data $41 \%$ siswa pernah melakukan hubungan seksual dan hampir 230.000 bayi lahir dari remaja. Komisi Perlindungan Anak Indonesia (KPAI) menyatakan sebanyak 32\% remaja di Kota Besar Indonesia (Jakarta, Surabaya, dan Bandung) pernah 5 berhubungan perilaku seksual. Hasil survei yang dilakukan oleh Durex Reckitt Benckiser RB Indonesia dengan JAKPAT pada 3 profil konsumen, yaitu anak muda, orang tua, dan pasangan menikah di 5 kota besar (Jakarta, Medan, Bandung, Surabaya dan Yogyakarta) diketahui bahwa pada responden remaja usia 18-20 Tahun, 33 persennya telah melakukan aktivitas seksual (Lis, 2019)

Penelitian-penelitian lain di Indonesia juga memperkuat gambaran adanya peningkatan kasus perilaku seksual remaja, seperti penelitian yang dilakukan Sedanayana (2015) kepada para siswa SMA di salah satu kecamatan di Kabupaten Buileleng dengan mengambil sampel 26 orang dari 57 orang siswa didapatkan bahwa $20 \%$ remaja telah melakukan hubungan seks sejak umur 15 tahun dan $80 \%$ pada umur 16 tahun. Di samping itu penelitian yang dilakukan oleh Lisnawati (2015) kepada SMK Cirebon menunjukan bahwa 58\% remaja sudah melakukan aktivitas seksual ringan, sedangkan $41,7 \%$ sudah melakukan aktivitas seksual berat.

Kasus perilaku seksual pada remaja di kota Pekanbaru Provinsi Riau juga sangat memprihatikan, Gerakan Nasional Anti Kekerasan Seksual Anak (GN-AKSA) tahun 2015 mencatat 97\% remaja sudah pernah melihat materi porno. Kasus ini kasus semakin membahayakan kaum remaja yang mana terjadi peningkatan yang signifikan dari tahun 2014 yang tercatat sebanyak $64 \%$ remaja suda pernah melakukan Kissing dari 12,4\% sudah pernah melakukan oral seks. Kejadian ini menjadi hal yang mengejutkan dan sangat memprihatikan dimana saat ini akses untuk mendapatkan gambar atau hal yang tidak baik sangatlah 
mudah karena kecanggihan teknologi.

Berdasarkan survei awal yang peneliti lakukan di SMK Telkom Pekanbaru, dengan mewawancarai atau menanyakan 10 orang siswa-siswi di SMK X Pekanbaru didapatkan 3 orang sudah memiliki pacar, 3 orang siswa mengatakan pernah merangkul bahu perempuan saat sedang jam istirahat berlangsung, 2 orang siswi pernah melakukan ciuman bibir dengan pasangannya, 2 orang siswa mengatakan pernah menonton film porno dan mengirim foto yang tidak sewajarnya. Setelah itu peneliti juga mengamati lingkungan sekolah SMK X Pekanbaru, di mana siswa-siswi saat jam istirahat berlangsung, banyak yang duduk berdampingan sambil tertawa, memegang wajah lawan jenisnya, dan berpegangan tangan. Lingkungan sekolah ada pasar dan sekolah terletak di dekat perumahan.

Siswa-siswi SMK Telkom Pakanbaru mengatakan bahwa di sekolah PIK-R (Pusat Informasi dan Konseling Remaja) tidak ada, tetapi sekolah memiliki guru BK (Bimbingan Konseling) yang masuk dalam kelas 1 kali seminggu. Guru BK lebih membahas tentang remaja yang nakal tidak perilaku seksual remaja yang sering terjadi pada remaja zaman sekarang.

Berdasarkan paparan diatas, maka tujuan penelitian ini adalah untuk mengidentifikasi hubungan lingkungan dengan perilaku seksual remaja di SMK X Pekanbaru.

\section{METODE PENELITIAN}

Penelitian ini merupakan penelitian kuantitatif dengan desain metode komparatif dan pendekatan cross-sectional. Penelitian ini dilakukan di SMK X Pekanbaru, diantara 245 orang siswa-siswi dengan menggunakan teknik cluster sampling pada 152 orang responden.

Pengumpulan data dilakukan dengan menggunakan kuesioner yang terdiri dari 2 macam kuesioner yang mengukur variabel perilaku seksual remaja dan lingkungan. Kuesioner variabel lingkungan disusun dengan beberapa pernyataan positif dan negatif yang harus diisi oleh responden.
Sementara kuesioner variabel perilaku seksual disusun dengan menggunakan semua pernyataan negatif.

Variabel dependen pada penelitian ini yaitu perilaku seksual remaja dengan hasil pengukuran menggunakan skala ordinal (perilaku seksual tidak berisiko dan perilaku seksual berisiko) dan variabel independennya lingkungan menggunakan skala nominal (baik dan tidak baik). Makin tinggi skor lingkungan responden, maka makin tidak baik lah lingkungan yang ada pada mereka. Sementara makin tinggi skor variabel perilaku seksual maka makin memiliki perilaku seksual yang berisiko.

Analisis bivariat yang digunakan dalam penelitian ini menggunakan chi square dan tidak ada satupun syarat uji chi square yang tidak terpenuhi dalam analisis penelitian ini. Proses penelitian dilakukan oleh peneliti sesuai dengan etika penelitian.

\section{HASIL DAN PEMBAHASAN}

Hasil Penelitian

Distribusi Frekuensi Jenis Kelamin Responden

Tabel 1. Jenis Kelamin Responden

\begin{tabular}{lcc}
\hline Jenis Kelamin & Frekuensi & Persentase (\%) \\
\hline Laki-laki & 97 & 64 \\
\hline Perempuan & 55 & 36 \\
\hline Total & 152 & 100 \\
\hline
\end{tabular}

Hubungan Perilaku Seksual dengan Lingkungan

Tabel 2. Hubungan Perilaku Seksual dengan Lingkungan

\begin{tabular}{cccc}
\hline & \multicolumn{2}{c}{ Perilaku Seksual } & \multirow{2}{*}{ Total } \\
\cline { 2 - 3 } Lingkungan & $\begin{array}{c}\text { Berisiko } \\
(\text { Jumlah(\%) })\end{array}$ & $\begin{array}{c}\text { Tak } \\
\text { Berisiko } \\
(\text { Jumlah(\%) })\end{array}$ & \\
\hline Baik & $37(24 \%)$ & $45(30 \%)$ & 82 \\
\hline Tak Baik & $44(29 \%)$ & $26(17 \%)$ & 70 \\
\hline Total & 81 & 53 & 152 \\
\hline & & P value $=0,043$
\end{tabular}


Pembahasan

Pada penelitian ini dapat disimpulkan bahwa terdapat hubungan yang signifikan antara lingkungan dengan perilaku seksual pada siswa di SMK X Pekanbaru (P value 0,043). Berdasarkan tabel 2 diketahui bahwa dari 82 responden memiliki lingkungan yang baik, terdapat 45 responden $(30 \%)$ tidak beresiko dalam perilaku seksual. Kemudian, pada lingkungan yang tidak baik terdapat 70 responden, sehingga 44 responden (29\%) beresiko pada perilaku seksual

Hasil penelitian ini sejalan dengan hasil penelitian yang dilakukan oleh Hayati (2017) bahwa pada penelitian tersebut memiliki hubungan yang sifnifikan antara lingkungan dengan perilaku seksual.

Penelitian ini juga senada dengan hasil yang dilakukan oleh Agustiani (2014) menunjukan hubungan yang sangat signifikan bahwa lingkungan menjadi pengaruh kuat terhadap remaja untuk melakukan perilaku seksual. Agustiani (2014) mengungkapkan ketika seorang anak tinggal dan bergaul dengan lingkungan yang salah, maka hancurlah masa depanya. Sebaliknya lingkungan yang agamis, penuh kasih sayang akan menimbulkan pribadi yang kuat dan cemerlang menatap masa depan. Peran lingkungan sosial menjadi pengaruh penting dalam mencetak pribadi seseorang (Candra, 2011). Suryoputro et al (2010) juga mengungkapkan banyak faktor yang menyebabkan remaja megalami perilaku seksual. Adapun beberapa fakor yang menyebabkan hal tersebut meliputi lingkungan, gaya hidup, teman sebaya, religiusitas, harga diri, pengendalian diri dan personal. Namun, yang menjadi faktor terkuat adalah lingkungan.

Notoatmodjo (2012), menjelaskan bahwa perilaku seksual memiliki 2 faktor yaitu, faktor internal dan faktor eksternal. Faktor internal adalah faktor dari diri kita atau bawaan seseorang sedangkan faktor eksternal adalah faktor dari lingkungan kita sekitar. Menurut Suhartono (2010) menyatakan bahwa lingkungan digolongkan menjadi tiga, yaitu : Lingkungan keluarga, yaitu disebutkan juga lingkungan pertama,
Lingkungan sekolah, yang disebutkan lingkungan kedua, lingkungan teman sebaya, yang disebutkan lingkungan ketiga.

Remaja lebih banyak berada diluar rumah dengan teman sebaya. Jadi dapat dimengerti bahwa sikap, pembicaraan, minat, penampilan dan perilaku teman sebaya lebih besar pengaruhnya daripada keluarga misalnya, jika remaja mengenakan model pakaian yang sama dengan pakaian anggota kelompok yang populer, maka kesempatan baginya untuk dapat diterima oleh kelompok lebih besar. Demikian pula bila anggota kelompok mencoba minum alkohol, rokok atau zat adiktif lainnya, maka remaja cenderung mengikuti tanpa mempedulikan akibatnya (Gunarsa, 2010). Pengaruh teman sebaya negatif memiliki perilaku seksual berat sebanyak $90.0 \%$ sedangkan pengaruh teman sebaya positif memiliki perilaku seksual tergolong berat $4 \%$ (Mesra \& Fauziah, 2016). Pengaruh negatif dari teman sebaya adalah gaya pergaulan bebas. Perilaku teman sebaya dalam kelompok menjadi acuan atau norma tingkah laku yang diharapkan dalam kelompok. Gaya berpacaran teman sebaya menjadi model atau acuan yang digunakan seseorang remaja dalam pacaran. Teman biasa melakukan ciuman dengan pacarnya, maka dibenarkan kalau dia juga berciuman. Remaja cenderung mengembangkan norma sendiri yang bertentangan dengan norma umum yang berlaku (Depari E. dalam Mesra \& Fauziah, 2016)

Media sosial dapat dikatakan sebagai lingkungan yang turut mempengaruhi perilaku seksual remaja (Sarwono, 2012). Kemajuan teknologi yang terjadi pada saat ini telah membawa dampak perubahan bagi masyarakat terutama pada remaja, baik itu dampak yang positif maupun dampak negatif. Kemajuan teknologi menyebabkan antar negara menjadi semakin mudah dan lancar, sehingga kebudayaan luar negeri lebih terasa pengaruhnya. Dampak yang paling 
terasa adalah pada tata budaya, moral, dan tata sosial masyarakat dan pada generasi muda khususnya.

Meskipun pemerintah Indonesia telah membuat blokade terhadap situs-situs yang menyediakan konten pornografi namun tidak dapat dipungkiri bahwasanya masyarakat tetap dapat mengakses konten pornografi menggunakan salah satu aplikasi melalui smartphone. Hal ini terlihat dari hasil penelitian ada $29 \%$ dari 82 siswa-siswi yang berada di lingkungan yang tidak baik juga memiliki perilaku seksual yang berisiko dan ada $24 \%$ dari 70 siswa-siswi yang meski berada di lingkungan yang baik namun perilaku seksualnya juga berisiko.

Kematangan fungsi seksual pada remaja dapat menimbulkan dorongan dan keinginan untuk pemuasan seksualnya dengan lawan jenis dalam bentuk pacaran atau percintaan (Hurlock, 2008). Faktor - faktor lain yang mempengaruhi remaja dalam berperilaku seksual adalah perubahan hormonal, penyebaran informasi melalui media masa penundaan usia perkawinan, tabu dan larangan dalam pembahasan perilaku seksual, norma - norma di masyarakat, dan pergaulan bebas remaja laki-laki dan perempuan (Sarwono, 2012).

Faktor-faktor yang mempengaruhi perilaku seks pranikah pada remaja diantaranya: faktor biologis, peran orang tua, pengaruh teman sebaya, faktor akademik, media massa (media internet (youtube) dan lingkungan pergaulan (Kusmiran, E. dalam Impartina, 2017). Dapat dimengerti fenomena yang terjadi pada remaja SMK X Pekanbaru terkait dengan perilaku seksual yang dilakukan oleh mereka memang ditunjang dari perkembangan biologis, sosial dan psikologisnya.

Perilaku seksual yang berisiko akan berdampak terhadap terjadinya pemudaran moral budaya timur sehingga pada akhirnya dapat meningkatkan kejadi aborsi ataupun pembuangan bayi yang dilakukan oleh remaja, meningkatnya kejadian HIV/AIDS ataupun penyakit menular seksual lainnya, pelecehan seksual hingga kriminalitas seperti melakukan sodomi atau pencabulan.

Meskipun jumlah siswa-siswi SMK X ini dikatakan rendah dalam hal perilaku seksual berisiko, namun ini bisa menjadi ancaman besar bagi siswa-siswi lainnya yang tidak memiliki perilaku berisiko.

Keadaan ini sedapat mungkin dapat menjadi perhatian para tenaga kesehatan seperti perawat puskesmas, guru BK, sekolah dan keluarga. Sekolah dapat mengantisipasi peningkatan kecendrungan perilaku seksual berisiko dengan meningkatkan kegiatan ekstrakurikuler siswa, memberikan edukasi seksual dan kesehatan dengan berkolaborasi dengan puskesmas seperti program PKPR (Pelayanan Kesehatan Peduli Remaja) dan meningkatkan kegiatan siraman rohani pada siswa-siswi di SMK tersebut serta menggunakan pendekatan pada keluarga seperti dengan melakukan FGD dan grup suportif untuk meningkatkan monitoring terhadap penggunaan gadget oleh siswa-siswi di rumah.

\section{SIMPULAN}

Temuan dari penelitian ini memperlihatkan bahwa perilaku seksual remaja berhubungan dengan lingkungannya. Artinya lingkungan dapat mempengaruhi perilaku seksual remaja, sehingga perlu perhatian dan bimbingan dari pihak sekolah, program puskesmas dan orang tua.

\section{DAFTAR PUSTAKA}

Agustiani (2014). Psikologi Perkembangan Pendekatan ekologi kaitannya dengan konsep diri \& penyesuaian Diri Pada Remaja. Bandung: Refika Aditama.

Candra (2011). Gambaran Perilaku Seksual Remaja SMK. Depok: UI

Cece. (2017). Analisis Faktor-faktor yang Berhubungan dengan Perilaksu Seks. Jurnal Kesesehatan Masyarakat. Dari https://www.ojs.uho.ac.id Diakses pada Tanggal 15 Oktober 2019 
Gunarsa, S. D. (2010). Psikologi Praktis: Anak, Remaja, dan Keluarga. Jakarta: Gunung Mulia

Hayati (2017). Hubungan Lingkungan Dengan Perilaku Seksual Pada Remaja. Jakarta: Rineka Cipta

Hurlock, E. B. (2008). Psikologi Perkembangan: Suatu Pendekatan Sepanjang Rentang Kehidupan. Jakarta: Erlangga

Impartina, A. (2017). Hubungan lingkungan pergaulan dengan Perilaku Seks Pranikah. Jurnal Riset Kebidanan Indonesia, Vol. 1, No. 2, Desember 2017: $35-40$

Irianto Koes. (2014). Permasalahan Seksual.Bandung: CV.Yrama Widya

Lis. (2019). Survei Terbaru: 33 Persen Remaja Usia 18-20 Tahun Telah Melakukan Hubungan Seksual. Wartakota.Tribunnews.com

Martopo. (2016). Tren Perilaku Remaja di Era Millenium. Jakarta: Erlangga

Mesra, E \& Fauziah. (2016). Pengaruh Teman Sebaya terhadap Perilaku Seksual Remaja. Jurnal Ilmiah Bidan. 1 (2).

Notoatmodjo S. (2012). Metodologi penelitian kesehatan. Jakarta: Rineka Cipta

Sarwono, S.W. (2012). Psikologi Remaja. Jakarta : Raja Grafindo Persada

Sendayana.G.(2015). Model Pengasuhan Analisis Transakonal (AT) Untuk Menanggulangi Penyimpangan Perilaku Seksual Di Kalangan Remaja Kabupaten Buleleng. Tidak publikasi. Universitas Pendidikan Ganesha Simga Raja Indonesia 